\title{
Approximate CAPM When Preferences Are CRRA
}

Citation for published version (APA):

Herings, P. J. J., \& Kubler, F. (2007). Approximate CAPM When Preferences Are CRRA. Computational Economics, 29, 13-31. https://doi.org/10.1007/s10614-006-9061-3

Document status and date:

Published: 01/01/2007

DOI:

10.1007/s10614-006-9061-3

Document Version:

Publisher's PDF, also known as Version of record

Document license:

Taverne

Please check the document version of this publication:

- A submitted manuscript is the version of the article upon submission and before peer-review. There can be important differences between the submitted version and the official published version of record.

People interested in the research are advised to contact the author for the final version of the publication, or visit the DOI to the publisher's website.

- The final author version and the galley proof are versions of the publication after peer review.

- The final published version features the final layout of the paper including the volume, issue and page numbers.

Link to publication

\footnotetext{
General rights rights.

- You may freely distribute the URL identifying the publication in the public portal. please follow below link for the End User Agreement:

www.umlib.nl/taverne-license

Take down policy

If you believe that this document breaches copyright please contact us at:

repository@maastrichtuniversity.nl

providing details and we will investigate your claim.
}

Copyright and moral rights for the publications made accessible in the public portal are retained by the authors and/or other copyright owners and it is a condition of accessing publications that users recognise and abide by the legal requirements associated with these

- Users may download and print one copy of any publication from the public portal for the purpose of private study or research.

- You may not further distribute the material or use it for any profit-making activity or commercial gain

If the publication is distributed under the terms of Article $25 \mathrm{fa}$ of the Dutch Copyright Act, indicated by the "Taverne" license above, 


\title{
Approximate CAPM When Preferences are CRRA*
}

\author{
P. JEAN-JACQUES HERINGS ${ }^{1}$ and FELIX KUBLER ${ }^{2}$ \\ ${ }^{1}$ Department of Economics, Maastricht University, P.O. Box 616, MD 6200 Maastricht, \\ The Netherlands. E-mail: P.Herings@algec.unimaas.nl; \\ ${ }^{2}$ Lehrstuhl für Wirtschaftstheorie, Universität Mannheim, 68131 Mannheim, Germany
}

Accepted 31 August 2006 / Published online: 21 October 2006

\begin{abstract}
In general equilibrium models of financial markets, the capital asset pricing formula does not hold when agents have von Neumann-Morgenstern utility with constant relative risk aversion. In this paper we examine under which conditions on endowments and dividends the pricing formula provides a good benchmark for equilibrium returns. While it is easy to construct examples where equilibrium returns are arbitrarily far from those predicted by CAPM, we show that there is a large class of economies where CAPM provides a very good approximation. Although the pricing formula does not hold exactly for the chosen specification, it turns out that pricing-errors are extremely small.
\end{abstract}

Key words: asset pricing, general equilibrium, incomplete markets.

JEL classification: D52; D58; G11; G12

\section{Introduction}

The Capital Asset Pricing Model (CAPM) of Sharpe (1964) and Lintner (1965) predicts that equilibrium returns of assets are a linear function of their market $\beta$, the slope in the regression of a security's return on the market's return. This intuitively appealing result has long shaped the way practitioners think about average returns and risk. While the empirical validity of the model is very controversial (see for example Fama and French (1992)), it remains one of the central building blocks in financial economics.

However, in consumption based asset pricing models where agents choose portfolios in order to maximize von Neumann-Morgenstern utility over non-negative

* This paper is a substantial revision of our 2000 METEOR working paper, "The Robustness of CAPM - A Computational Approach”. The research of Jean-Jacques Herings has been made possible by a fellowship of the Royal Netherlands Academy of Arts and Sciences and a grant of the Netherlands Organisation for Scientific Research (NWO). While this paper was being written this author enjoyed the generous hospitality of the Cowles Foundation for Research in Economics at Yale University, of CORE at Université Catholique de Louvain, and of CentER at Tilburg University. Felix Kubler gratefully acknowledges the financial support of the Cowles Foundation in the form of an Anderson dissertation fellowship. 
consumption processes, the CAPM pricing formula only holds if one assumes that all agents' utility functions are quadratic (see Geanakoplos and Shubik, 1990; Berk, 1997). This is generally recognized as an unrealistic specification of preferences, for instance because it implies increasing absolute risk aversion. Instead, it is generally agreed upon that agents' preferences exhibit decreasing absolute risk-aversion and non-decreasing relative risk aversion. As a consequence, the CAPM pricing formula will fail to hold.

The fact that the CAPM pricing formula fails to hold does not imply that it does not hold approximately, and might therefore still be useful for practical purposes. For the related problem of portfolio choice, it has been shown by various authors that mean-variance analysis is valid in the limit, when either risk is small in absolute terms (Samuelson, 1970) or risk is small relative to wealth as discussed by Tsiang (1972).

In this paper we investigate under which conditions equilibrium asset prices can be well approximated by the CAPM formula in economies where all agents have constant relative risk aversion preferences (CRRA) and where individual income uncertainty is relatively modest. For the problem of portfolio selection, this question has also been addressed in Levy and Markowitz (1979). They show that portfolios are well approximated by the model when individuals have either constant absolute risk aversion (CARA) or CRRA-preferences, where CRRA-preferences correspond to the most difficult case.

In applied general equilibrium, the assumption of CRRA is popular, see for instance the paper of Mehra and Prescott (1985) and much of the work that followed it. In infinite horizon models with growth this specification of utility is necessary for obtaining a balanced growth path. CRRA has been tested nonparametrically and found confirmed by Tversky and Kahneman (1992). Also Arrow (1965) argues in favor of CRRA, arguing that relative risk aversion "must hover around 1" (p. 37). For these reasons, we consider the CRRA-case the most relevant one, and stick to these types of preferences in this paper. ${ }^{1}$ Under this assumption CAPM does not hold and there are no general results linking an asset's equilibrium return to its covariance with the market's return.

It is easy to construct examples where assets' market $\beta$ does not explain any variation in cross sectional returns. In these economies any econometric test would reject CAPM and empirical contradictions of CAPM might be explained by the fact that some agents do not have quadratic utility. For example, when all assets have the same price and each asset payoff has the same covariance with aggregate endowments, CAPM predicts that the excess returns must be identical across assets. But since higher moments matter when agents have CRRA preferences the equilibrium returns generally differ across assets. We give a simple example where these differences are quantitatively substantial.

On the other hand we argue by means of a computational approach that for a large class of economies the CAPM pricing formula provides a very good prediction for actual equilibrium returns. 
It is clear that the examples we provide may not be representative of real life scenarios. It is well documented in the literature that extensions and modifications of standard CAPM outperform the original model (see e.g. Dittmar, 2002). However, we do believe that our examples are interesting because they describe a large class of economies where standard CAPM does very well. In our examples, utility functions are not well approximated by a low-order Taylor expansion, yet the general equilibrium implications are similar to CAPM. These examples imply that empirical evidence against the validity of CAPM cannot simply be explained by the fact that individuals do not have quadratic utility. Downside risk and skewness in return distributions (as for example empirically documented in Ang et al. (2005)) must be a crucial ingredient for any explanation of why CAPM fails empirically.

We consider economies with three agents and 32,768 states of nature and we examine the robustness of CAPM with respect to different specifications of preferences, payoffs and endowments. We assume that the agents have CRRA utility functions (but different degrees of risk aversion) and examine the following cases:

- Endowments and dividends are drawn from a uniform distribution. We randomly generate 100 economies which differ with respect to the support of the uniform distributions.

- Endowments and dividends are drawn from a log-normal distribution. We randomly generate 100 economies which differ with respect to the agents' coefficients of risk aversion.

- Endowments and dividends are determined by two factors and an idiosyncratic shock each of which is drawn from a log-normal distribution. We randomly generate 100 economies which differ with respect to the factor-loads.

- Endowments and dividends are drawn from a log-normal distribution and there is an option on one of the stocks. We randomly generate 100 economies which differ with respect to the strike-price of the option.

For all economies under consideration we compare the computed return on individual stocks to the return predicted by the CAPM-pricing formula. We find that in all 400 cases the average mean squared pricing errors (for returns) across stocks lie below $0.04 \%$. The average error across all simulations is in the order of magnitude of $0.005 \%$. In these economies standard statistical procedures would accept CAPM.

The paper is organized as follows. In Section 2 we introduce the general equilibrium model and summarize several results on CAPM in this setting. We give a simple example that demonstrates that CAPM may fail to hold in our setup. In Section 3 we provide a novel way to measure how well CAPM returns approximate actual returns, and compute this measure for several hundred examples. We show that CAPM does very well in an approximate sense for all cases considered. Section 4 concludes. 


\section{The Two-Period Finance Economy}

The finance version of the general equilibrium model with incomplete asset markets (GEI-model) describes an economy over two periods of time, $t=0,1$, with uncertainty over the state of nature resolving in period $t=1$. We describe the model, introduce the necessary notation and discuss the CAPM. For a thorough description of the GEI-model see for example Magill and Quinzii (1996).

\subsection{THE MODEL}

There are $S+1$ states in the economy; at time $t=0$ the economy is in state $s=0$, at time $t=1$ one state of nature $s$ out of $S$ possible states of nature realizes. In each state $s=0, \ldots, S$, there is a single non-durable consumption good.

There are $H$ agents, indexed by $h=1, \ldots, H$, that participate in the economy. An agent $h$ is characterized by initial endowments (the initial income stream) $e^{h}=\left(e_{0}^{h}, e_{1}^{h}, \ldots, e_{S}^{h}\right)^{\top} \in \mathbb{R}_{++}^{S+1}$. Here $e_{s}^{h}$ denotes the amount of income of agent $h$ available for consumption in state of nature $s$ when the agent abstains from trading. In particular, $e_{0}^{h}$ is the amount of income available for consumption at $t=0$ and $\left(e_{1}^{h}, \ldots, e_{S}^{h}\right)$ denotes the random amount of income available for consumption at $t=1$. To distinguish between amounts of income $\mathrm{t} t=0$ and random amounts of income at $t=1$, we define $\widetilde{x}=\left(x_{1}, \ldots, x_{S}\right)^{\top}$ for any vector $x=\left(x_{0}, x_{1}, \ldots, x_{S}\right)^{\top}$. Aggregate endowments (aggregate incomes) are $e=\sum_{h=1}^{H} e^{h}$.

Agents have preferences over consumption bundles (income streams available for consumption) $c^{h}=\left(c_{0}^{h}, c_{1}^{h}, \ldots, c_{S}^{h}\right)^{\top} \in \mathbb{R}_{+}^{S+1}$. Each agents' preferences are represented by a von Neumann-Morgenstern utility function

$$
u^{h}\left(c^{h}\right)=v^{h}\left(c_{0}^{h}\right)+\delta \sum_{s=1}^{S} \rho_{s} v^{h}\left(c_{s}^{h}\right),
$$

where $\rho_{s}$ denotes the probability of occurrence of future state of nature $s, \delta$ is a discount factor, and $v^{h}$ is the Bernoulli function that measure instantaneous utility derived from consumption $c_{s}^{h}$ by agent $h$ in state of nature $s$. We assume that $\rho_{1}, \ldots, \rho_{S}>0, \sum_{s=1}^{S} \rho_{S}=1, \delta>0$, that probabilities and the discount factor are identical across agents, and that the Bernoulli function $v^{h}: \mathbb{R}_{+} \rightarrow \mathbb{R}$ is assumed to be strictly increasing and strictly concave.

There are $J$ assets. Asset $j$ pays (random) dividends at date $t=1$ which we denote by $d_{j} \in \mathbb{R}^{S}$. The price of asset $j$ at time $t=0$ is $q_{j}$. Without loss of generality, we assume in this section that the assets are in zero net supply, i.e., the trades by agents are the agents' net trades, and we collect all assets' dividends in a pay-off matrix

$$
A=\left(d_{1}, \ldots, d_{J}\right) \in \mathbb{R}^{S \times J} .
$$

Without loss of generality, we assume $A$ to have full column rank. ${ }^{2}$ 
At time $t=0$ agent $h$ chooses a portfolio-holding $\theta^{h}=\left(\theta_{1}^{h}, \ldots, \theta_{J}^{h}\right) \in \mathbb{R}^{J}$ which uniquely defines the agents' consumption by $\widetilde{c}^{h}=\widetilde{e}^{h}+A \theta^{h}$ and $c_{0}^{h}=e_{0}^{h}-\theta^{h} \cdot q$. The net demand of agent $h, \widetilde{c}^{h}-\widetilde{e}^{h}$, therefore belongs to the so-called marketed subspace $\langle A\rangle=\left\{z \in \mathbb{R}^{S} \mid \exists \theta \in \mathbb{R}^{J}, z=A \theta\right\}$.

The exogenous parameters defining a finance economy $\mathcal{E}=\left(\left(u^{h}, e^{h}\right)_{h=1, \ldots, H} ; A\right)$ are agents' utility functions and endowments, and the pay-off matrix.

We define asset prices to be arbitrage free if it is not possible to achieve a positive income stream in all states by trading in the available assets. It is well known that a price system $q \in \mathbb{R}^{J}$ precludes arbitrage if and only if there exists a state price vector $\pi \in \mathbb{R}_{++}^{S}$ such that $q=\pi^{\top} A$.

DEFINITION 1. (Competitive Equilibrium): A competitive equilibrium for an economy $\mathcal{E}$ is a collection of portfolio-holdings $\theta^{*}=\left(\theta^{1 *}, \ldots, \theta^{H *}\right) \in \mathbb{R}^{H J}$, consumptions $c^{*}=\left(c^{1 *}, \ldots, c^{H *}\right)$ and asset prices $q^{*} \in \mathbb{R}^{J}$ that satisfy the following conditions:

(1) $\left(c^{h *}, \theta^{h *}\right) \in \arg \max _{c^{h}, \theta^{h}} u^{h}\left(c^{h}\right)$ s. $\quad$ t. $c^{h}=e^{h}+\left(\begin{array}{c}-q^{*^{\top}} \\ A\end{array}\right) \theta^{h}$ and $c^{h} \in \mathbb{R}_{+}^{S+1}$, $h=1, \ldots, H$;

(2) $\sum_{h=1}^{H} \theta^{h *}=0$.

Existence of an equilibrium follows from the results of Geanakoplos and Polemarchakis (1986).

\subsection{THE CAPITAL ASSET PRICING MODEL}

Under the assumption that all agents are mean-variance optimizers, Sharpe (1964) and Lintner (1965) derive a closed-form solution for equilibrium returns, the socalled $\beta$-pricing formula. This formula relates the return of a risky asset to the return of the market portfolio by the covariance of that asset with the market. It is well known that the $\beta$-pricing formula can be derived in the finance GEI-model as presented in the previous subsection, see Geanakoplos and Shubik (1990). We summarize the findings in the literature (Geanakoplos and Shubik, 1990; Magill and Quinzii, 1996; Oh, 1996; Willen, 1997) in order to define appropriate ways to measure deviations from CAPM in Section 3.

We denote by $1_{n}=(1, \ldots, 1)^{\top} \in \mathbb{R}^{n}$ the vector of all ones. We assume that asset 1 is a riskless bond, so $d_{1}=1_{S}$. For a random variable $x \in \mathbb{R}^{S}$, we define its expected value $\mathrm{E}(x)=\sum_{s=1}^{S} \rho_{s} x_{s}$, for two random variables $x, y \in \mathbb{R}^{S}$, we define the covariance as $\operatorname{cov}(x, y)=\sum_{s=1}^{S} \rho_{s} x_{s} y_{s}-\mathrm{E}(x) \mathrm{E}(y)$. The variance of a random variable $x \in$ $\mathbb{R}^{S}$ is given by $\operatorname{var}(x)=\operatorname{cov}(x, x)$. Finally, we define $x \cdot \rho y=\sum_{s=1}^{S} \rho_{s} x_{s} y_{s}$ for vectors $x, y \in \mathbb{R}^{S}$.

Given asset prices $q \in \mathbb{R}^{J}$, we define the return of a portfolio $\theta \in \mathbb{R}^{J}$ with $q \cdot \theta \neq 0$ by $r_{\theta}=A \theta / q \cdot \theta$ and we denote the return of the riskless bond by $R^{\mathrm{f}}=1 / q_{1}$. 
For any competitive equilibrium $\left(\theta^{*}, q^{*}\right)$, the absence of arbitrage implies that there exists at least one state price vector $\pi \in \mathbb{R}_{++}^{S}$ such that, for all assets $j, q_{j}^{*}=\pi \cdot \rho d_{j}$. It is easy to show and well-known that if one projects any state price vector $\pi \in \mathbb{R}_{++}^{S}$ for which, for all assets $j, q_{j}^{*}=\pi \cdot{ }_{\rho} d_{j}$, onto the marketed subspace $\langle A\rangle$, one obtains a unique pricing vector, denoted by $\pi_{A}^{*}$. For example, under the assumption that one agent $h$ 's utility function is differentiable and that in an equilibrium with individual consumption $\left(c^{h *}\right)_{h \in H}$, agent $h$ 's utility maximization problem has an interior solution, $\pi_{A}^{*}$ can be characterized as

$$
\pi_{A}^{*}=\operatorname{proj}_{\langle A\rangle}\left(\frac{\partial_{c_{1}^{h}} u^{h}\left(c^{h *}\right) / \rho_{1}}{\partial_{c_{0}^{h}} u^{h}\left(c^{h *}\right)}, \ldots, \frac{\partial_{c_{S}^{h}} u^{h}\left(c^{h *}\right) / \rho_{S}}{\partial_{c_{0}^{h}} u^{h}\left(c^{h *}\right)}\right),
$$

where $\operatorname{proj}_{\langle A\rangle}$ denotes the projection on $\langle A\rangle$ under the inner product $\rho$. The assumption of mean-variance utility allows for a sharp prediction on $\pi_{A}^{*}$ which does not hold in general for other specifications of utility. Below we will use this deviation as a measure of how well CAPM holds.

In general, agent $h$ 's first period endowments can be decomposed into a marketed part and a non-marketed part, where the latter part lies orthogonal to the marketed subspace under the inner product $\rho$. More precisely,

$$
\widetilde{e}^{h}=\widetilde{e}_{\mathrm{M}}^{h}+\widetilde{e}_{\perp}^{h},
$$

where by definition $\widetilde{e}_{\mathrm{M}}^{h}=\operatorname{proj}_{\langle A\rangle} \widetilde{e}^{h}$ and $\widetilde{e}_{\perp}^{h}=\widetilde{e}^{h}-\widetilde{e}_{\mathrm{M}}^{h}$. Moreover, by definition, $\widetilde{e}_{\perp}^{h} \cdot \rho z=0$ for all $z \in\langle A\rangle$. This decomposition is uniquely determined. We define the marketed endowments by $\widetilde{e}_{\mathrm{M}}=\sum_{h=1}^{H} \widetilde{e}_{\mathrm{M}}^{h}$. The market portfolio $\theta_{\mathrm{M}}$ is then defined as the unique portfolio satisfying

$$
A \theta_{\mathrm{M}}=\widetilde{e}_{\mathrm{M}} .
$$

For a competitive equilibrium $\left(\theta^{*}, c^{*}, q^{*}\right)$, we define $\beta_{\theta}$ for a portfolio $\theta \in \mathbb{R}^{J}$ by

$$
\beta_{\theta}=\frac{\operatorname{cov}\left(r_{\theta}, r_{\theta_{M}}\right)}{\operatorname{var}\left(r_{\theta_{M}}\right)} .
$$

Then the following result can be found in the literature (see e.g. Willen (1997) for a derivation in the GEI-framework).

THEOREM 1. Under the assumptions that all agents have quadratic utility, that $\operatorname{var}\left(\widetilde{e}_{M}\right)>0$, and that there is a riskless bond, each equilibrium $\left(\theta^{*}, c^{*}, q^{*}\right)$ of $\mathcal{E}$ with equilibrium consumption $\left(c^{1 *}, \ldots, c^{H *}\right) \gg 0$ has the following properties. ${ }^{3}$

1. The CAPM-pricing formula holds; when $q^{*} \cdot \theta_{M} \neq 0$, then for each $\theta \in \mathbb{R}^{J}$,

$$
E\left(r_{\theta}\right)-R^{\mathrm{f}}=\beta_{\theta}\left(E\left(r_{\theta_{\mathrm{M}}}\right)-R^{\mathrm{f}}\right) .
$$


2. The pricing vector satisfies $\pi_{A}^{*}=\alpha_{1} 1_{S}-\alpha_{2} \widetilde{e}_{\mathrm{M}}$, with $\alpha_{1}>\alpha_{2} \mathrm{E}\left(\widetilde{e}_{\mathrm{M}}\right)$ and $\alpha_{2}$ strictly positive.

Note that for the case where the endowments are spanned, i.e. where $e_{\perp}^{h}=0$ for all $h$, the pricing formula reduces to the standard CAPM-formula (see Magill and Quinzii, 1996). This is the (rather restrictive) case that is typically considered in the finance literature. Theorem 1 shows that for an appropriate definition of the market portfolio, the standard CAPM-result with spanned endowments can be generalized substantially.

It might be sensible to define the market portfolio somewhat differently as a portfolio of risky assets only. In this case define $\widehat{\theta}_{\mathbf{M}}=\left(0, \theta_{\mathbf{M}, 2}, \ldots, \theta_{\mathbf{M}, J}\right)$. If we define $\widehat{\beta}_{\theta}=\operatorname{cov}\left(r_{\theta}, r_{\widehat{\theta}_{M}}\right) / \operatorname{var}\left(r_{\widehat{\theta}_{M}}\right)$ it turns out that the pricing formula still holds. After some substitutions, one obtains

$$
\mathrm{E}\left(r_{\theta}\right)-R^{\mathrm{f}}=\widehat{\beta}_{\theta}\left(\mathrm{E}\left(r_{\widehat{\theta}_{\mathrm{M}}}\right)-R^{\mathrm{f}}\right) .
$$

\subsection{AN EXAMPLE}

As we have discussed in the introduction, Theorem 1 can only be obtained when one is willing to make very restrictive assumptions. Magill and Quinzii (1996), page 140, comment on the CAPM: "As we indicated above these models are interesting since they lead to clearcut results which have strong intuitive appeal. However the restrictive nature of the hypothesis made could cast doubt on the generality of the results." In particular, the assumption that all agents maximize a quadratic utility function is unattractive because it implies increasing absolute risk aversion. A more realistic assumption, and one commonly made in macroeconomics and finance, is that agents' preferences exhibit CRRA. The question we want to address in this paper is how much actual equilibrium prices will differ from the predictions of CAPM in this more realistic setting.

We give a simple example that shows that the CAPM pricing formula might be completely useless for explaining cross sectional returns. Consider an economy with a representative agent with CRRA utility function, so the utility function of the agent has the form

$$
\begin{array}{ll}
v(c)=\frac{c^{1-\gamma}}{1-\gamma}, & \gamma \neq 1, \\
v(c)=\log (c), & \gamma=1,
\end{array}
$$

where $\gamma$ is the coefficient of relative risk aversion. The agent's initial endowments consist of his labor income plus dividends from his asset holdings. In addition to a bond there are two risky stocks which are independently distributed. There are two independently distributed factors, $\varepsilon^{1}$ and $\varepsilon^{2}$. The first factor is 0.8 with probability $2 / 3$ and 1.4 with probability $1 / 3$. The second factor is 1.2 with probability $2 / 3$ and 0.6 with probability $1 / 3$. The two stocks' dividends are

$$
d_{1}=\varepsilon^{1} \text { and } d_{2}=\varepsilon^{2}+\mu 1_{S}
$$


for some $\mu \geq 0$. The agent initially holds one unit of both stocks. The agent has a non-stochastic labor income of $0.2-\mu$ in the second period. Suppose the agent also has 2 units available for consumption in the first period and does not discount the future, i.e. $\delta=1$. It follows that $\tilde{e}=0.2+\varepsilon^{1}+\varepsilon^{2}$.

For $\mu=E\left(\left(\varepsilon^{1}-\varepsilon^{2}\right) / \tilde{e}^{\gamma}\right) / E\left(1 / \tilde{e}^{\gamma}\right)$ the equilibrium prices of the two stocks are identical. Since both stocks have the same covariance with aggregate endowments, CAPM predicts that the excess return of the two stocks must be equal. However, the equilibrium excess returns are quite different and depend on $\gamma$ as in Table I.

The key to this example lies in the fact that on the margin, a CRRA agent prefers the dividends of asset 1 to the dividends of asset 2 - therefore for the same expected payoffs, asset 2 must be cheaper than asset 1 and its returns higher. A mean-variance agent with quadratic utility, on the other hand, would be indifferent between $\varepsilon^{1}$ and $\varepsilon^{2}$ since they have the same mean and variance.

Surprisingly, the next section will be used to demonstrate that this example crucially depends on the specific construction used to define dividends and to relate dividends to labor income. We show that, contrary to the example, for realistically calibrated economies, returns predicted by CAPM provide excellent approximations to actual equilibrium returns.

\section{Robustness of CAPM}

In applied general equilibrium, the assumption of CRRA is popular, see for instance the paper of Mehra and Prescott (1985) and much of the work that followed it. CRRA has been tested non-parametrically and found confirmed by Tversky and Kahneman (1992). Also Arrow (1965) argues in favor of CRRA, arguing that relative risk aversion "must hover around 1" (p. 37). We will therefore assume CRRA utility functions for all agents in our economies.

We test the robustness of our results to variations in the distributions of endowments and assets. We consider three different families of return processes and compute 100 randomly generated examples within each class. We show the histograms of two measures to be introduced in the sequel, called MSE and Pricing $R^{2}$, that measure how well CAPM-pricing approximates equilibrium pricing. In all histograms the scaling is taken identically, so that results for different models can be compared easily.

Table I. Equilibrium excess returns.

\begin{tabular}{lllc}
\hline$\gamma$ & Excess return 1 & Excess return 2 & CAPM prediction \\
\hline 2 & 7.7 & 10.1 & 8.9 \\
4 & 13.7 & 20.7 & 17.2 \\
6 & 15.2 & 25.7 & 20.4 \\
\hline
\end{tabular}




\subsection{HETEROGENEOUS AGENTS AND IDENTICAL FACTORS}

One has to compute equilibria in order to assess how well CAPM predicts equilibrium prices in economies with heterogeneous agents and incomplete markets. From now on we examine economies with three heterogeneous agents, representing classes of agents with low, medium and high incomes.

Agents have heterogeneous von Neumann-Morgenstern utility functions with constant relative risk aversion, identical uniform probabilities over states and identical discount factors $\delta^{h}=0.95$. We choose heterogeneous coefficients of risk aversion: $\gamma^{1}=6, \gamma^{2}=4$ and $\gamma^{3}=2$, i.e. the lower the income, the higher the coefficient of relative risk aversion of the agent.

Each agent is endowed with an initial portfolio of assets and a set of contractual obligations to provide labor services, yielding labor income. The initial asset portfolio consists of 0 units of a riskless bond and $\theta_{-}^{h} \in \mathbb{R}^{J-1}$ units of the available stocks. We assume that the first agent has no capital income, $\theta_{-}^{1}=0$. For the other agents we have $\theta_{-}^{2}=1 / 3 \cdot 1_{J-1}$ and $\theta_{-}^{3}=2 / 3 \cdot 1_{J-1}$.

Labor income consists of current labor income $l_{0}^{h}$ and stochastic future labor income $l^{h} \in \mathbb{R}_{++}^{S}$. The initial endowments at $t=0$ are therefore equal to previous dividends from $\theta_{-}^{h}$ plus labor income, and are set equal to $e_{0}^{1}=2 / 3, e_{0}^{2}=1$, and $e_{0}^{3}=4 / 3$. The initial endowments at $t=1$ equal

$$
\widetilde{e}^{h}=\sum_{j=2}^{J} \theta_{-, j}^{h} d_{j}+l^{h} .
$$

In the examples we represent the available assets by a riskless bond and seven representative stocks. In most examples the dividends of asset $j$ depend on a single common factor which we now denote by $f \in \mathbb{R}^{S}$ as well as on an idiosyncratic factor $\varepsilon^{j} \in \mathbb{R}^{S}$. We denote asset $j$ 's load in the common factor by $\phi_{j}$, varying from 0.25 to 1.75 in steps of 0.25 . In most examples, $f$ and $\varepsilon^{j}$ are $S$-dimensional approximations of continuously distributed random variables. In these cases, we set $S=32,768$. Using a large number of states guarantees that our final samples are good approximations of continuous distributions. By taking a large number of states we rule out finite sample effects on the prices of assets. When we replicate the experiment and generate economies out of a newly drawn sample, the equilibrium will be almost the same if the number of states is sufficiently large.

Similar to the way $f$ and $\varepsilon^{j}$ are constructed, we generate for each household $h$ the labor incomes $l_{s}^{h}$ by $S$ independent draws from some given distribution. The eleven random variables in the model are therefore $\left(\left(l^{h}\right)_{h=1, \ldots, H}, f,\left(\varepsilon^{j}\right)_{j=2, \ldots, J}\right)$.

Aggregate consumption and capital share in the examples are calibrated to yearly US data. The expected growth rate of aggregate consumption equals two percent and the standard deviation of both the factor and the idiosyncratic shock determining the dividends areabout 0.13 - giving an overall standard deviation 
of the stock market of about 0.17. The standard deviation of labor income is chosen to be around 0.10 and labor income constitutes around 2/3 of total income.

As a first example we analyze the case where the realization of each random variable is either high or low with equal probability, and all random variables are independent. The minimal state space to achieve this consists of $2^{11}=2,048$ states. More specifically we have that

$$
\begin{aligned}
& l_{s}^{h} \in\{2 / 3 \cdot(1.02-0.1), 2 / 3 \cdot(1.02+0.1)\}, \\
& f_{s} \in\{-0.13,0.13\}, \\
& \varepsilon_{s}^{j} \in\{-0.13,0.13\} .
\end{aligned}
$$

Dividends of asset $j$ are then determined by

$$
d_{s}^{j}=1 / 3 \cdot 1 / 7 \cdot\left(1.02+\sqrt{\phi_{j}} f_{s}+\varepsilon_{s}^{j}\right) .
$$

We have taken the square-root of the factor load $\phi_{j}$ in the specification of the dividends in order to give it an interpretation as the (approximate) stock's market $\beta$.

With these specifications we compute the equilibrium prices and portfolio holdings and compare them to the predictions of the CAPM in Figure 1. In Herings and Kubler (2002) we develop an algorithm that is tailored to the finance GEI-model with one good per state, and that is independent of the number of states. We use this algorithm to approximate equilibria numerically.

The solid line in the figure is the security market line, i.e. the CAPM relationship between a portfolio's $\beta$ and its risk premium. The actual equilibrium expected returns of the seven securities are depicted by + and lie all almost exactly on the

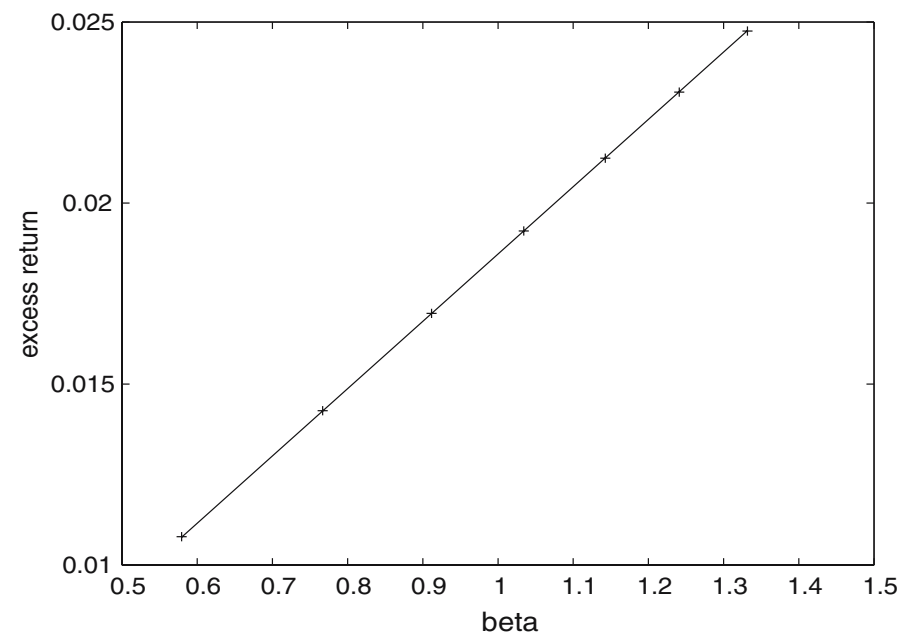

Figure 1. Security market line with high-low returns. 
security market line. CAPM turns out to be an extraordinarily good predictor for the actual equilibrium returns of assets in this example. This is surprising for two reasons. First, the asset payoffs and dividends do not satisfy the assumptions in Section 2.2. Secondly, the introduction of agents' heterogeneity does not alter the cross section of equilibrium returns significantly.

Although the graph of Figure 1 looks very convincing, it is clear that we need more objective measures to quantify the deviation of equilibrium prices and portfolio-holdings from the CAPM predictions.

The most straightforward approach to measure the accuracy of CAPM-pricing is to take the Mean Squared Error (MSE), which is defined by

$$
\mathrm{MSE}=\sqrt{\frac{1}{J-1} \sum_{j=2}^{J}\left(r_{j}^{*}-\widehat{r}_{j}\right)^{2},}
$$

where $r_{j}^{*}$ denotes the equilibrium expected return of asset $j$ and $\widehat{r}_{j}$ the prediction by CAPM, using (1) and the true equilibrium interest rates and market return.

A different approach consists of the following. It is well-known that $\pi_{A}^{*} \in\left\langle 1_{S}, \widetilde{e}_{\mathrm{M}}\right\rangle$ is sufficient for CAPM-pricing. That this is necessary as well follows from the observation that otherwise $\pi_{A}^{*}$ is equal to the sum of its projection on $\left\langle 1_{S}, \widetilde{e}_{\mathrm{M}}\right\rangle$ plus a non-zero orthogonal part in $\langle A\rangle$ under the inner product $\rho$. When CAPM-pricing is valid, the orthogonal part should have zero price, which is obviously not the case when priced by $\pi_{A}^{*}$. Therefore, an interesting alternative to MSE is to take the OLS $R^{2}$ of the regression with

$$
\operatorname{proj}_{\langle A\rangle}\left(\frac{\partial_{c_{1}^{h}} u^{h}\left(c^{h *}\right) / \rho_{1}}{\partial_{c_{0}^{h}} u^{h}\left(c^{h *}\right)}, \ldots, \frac{\partial_{c_{S}^{h}} u^{h}\left(c^{h *}\right) / \rho_{S}}{\partial_{c_{0}^{h}} u^{h}\left(c^{h *}\right)}\right)
$$

as regressand and $1_{S}$ and $\widetilde{e}_{M}$ as regressors. Notice that this measure is independent of $h$. We call it Pricing $R^{2}$.

We believe that our approach of assessing the validity of CAPM-pricing is both novel and appropriate. Since this equilibrium state price vector is equal to the projection of the equilibrium marginal utility vector of all agents on the marketed subspace, it can be used for pricing all marketed securities. When the pricing $R^{2}$ is close to one, actual equilibrium returns of securities will be close to the CAPMpredictions.

Table II confirms that CAPM provides an outstanding prediction for the economy under consideration.

\subsection{UNIFORM RETURNS}

In order to verify whether our results depend crucially on all factors having the same distribution we now assume uniformly distributed shocks, which all have different support. We also allow for some variation in the ratio of labor income 
to total income, in the variance of the factor and in the variance of the idiosyncratic shocks.

More specifically, we start each example by randomly generating parameters $a_{1}, a_{2}, a_{3}$ and $a_{4}$, where

$$
\begin{aligned}
& a_{1} \sim \mathrm{U}(1.02 \cdot 0.5,1.02 \cdot 0.9), \\
& a_{2} \sim \mathrm{U}(1.02 \cdot 1.1,1.02 \cdot 1.5), \\
& a_{3} \sim \mathrm{U}(-0.5,-0.1), \\
& a_{4} \sim \mathrm{U}(0.1,0.5) .
\end{aligned}
$$

Given a realization for $a_{1}, \ldots, a_{4}$, we continue the construction of the economy by taking independent drawings for $l_{s}^{h}, f_{s}$ and $\varepsilon_{s}^{j}$, where

$$
\begin{aligned}
l_{s}^{h} & \sim \mathrm{U}(2 / 3 \cdot 0.8,2 / 3 \cdot 1.24), \\
f_{s} & \sim \mathrm{U}\left(\left(a_{1}-a_{2}\right) / 2,\left(a_{2}-a_{1}\right) / 2\right), \\
\varepsilon_{s}^{j} & \sim \mathrm{U}\left(a_{3}, a_{4}\right) .
\end{aligned}
$$

Finally, dividends are determined by

$$
d_{s}^{j}=1 / 3 \cdot 1 / 7 \cdot\left(\frac{a_{1}+a_{2}}{2}+\sqrt{\phi_{j}} f_{s}+\varepsilon_{s}^{j}\right) .
$$

Given the realizations for the parameters $a_{1}$ and $a_{2}, 1 / 3 \cdot 1 / 7 \cdot\left(a_{1}+a_{2}\right) / 2$ equals expected dividends from asset $j$. The realization of the factor belongs to the interval $\left[\left(a_{1}-a_{2}\right) / 2,\left(a_{2}-a_{1}\right) / 2\right]$ and the realizations of the idiosyncratic shocks to the interval $\left[a_{3}, a_{4}\right]$. The expected labor income and the variance of labor income are taken as before.

Figure $2 \mathrm{a}, \mathrm{b}$ shows that the ability of CAPM to predict portfolio-holdings and excess returns is robust to variations in the distribution of shocks.

Figure 2 shows that CAPM is an excellent predictor for the class of CRRA utility functions and uniform factors. While the factors are no longer iid, in most cases the MSE is around $1 \times 10^{-4}$. The worst Pricing $R^{2}$ found is 0.9999 .

The high values of the Pricing $R^{2}$ provides very useful information for the pricing of assets. Recall that the price of asset $j$ is given by $\pi_{A}^{*} \cdot d^{j}$. Any vector that

Table II. CAPM for CRRA preferences and two-point distributions.

\begin{tabular}{ll}
\hline$R^{\mathrm{f}}$ & 1.0633 \\
Equity Premium & 0.0185 \\
MSE & 0.0000530 \\
Pricing $R^{2}$ & 0.99999998 \\
\hline
\end{tabular}



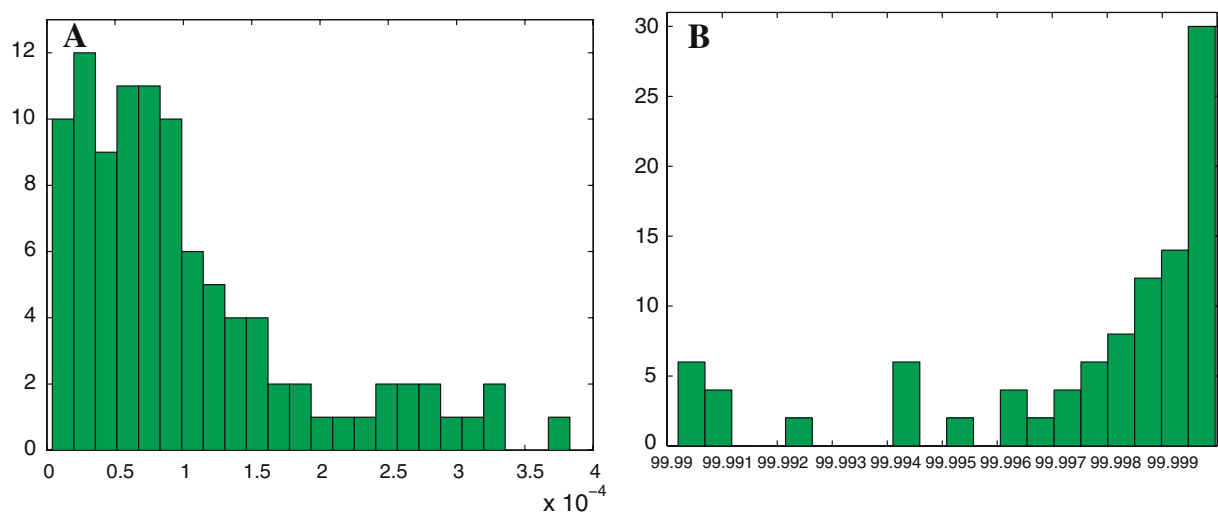

Figure 2. (a) Uniform: MSE, (b)Uniform: 100. Pricing $R^{2}$.

is highly correlated with $\pi_{A}^{*}$ should lead to a similar price for asset $j$. In particular, when the Pricing $R^{2}$ is close to one, CAPM is bound to give almost exact equilibrium prices and the use of CAPM leads to a low MSE.

\subsection{LOG-NORMAL RETURNS AND DIFFERENT RISK AVERSIONS}

We now vary the factor structure further by assuming that all asset payoffs are the product of iid factors with log-normal distribution. Furthermore, we vary agents' degree of risk aversion.

Throughout this section we assume that all random variables are log-normally distributed, so $l_{s}^{h}, f_{s}$, and $\varepsilon_{s}^{j}$ are drawn independently from a log-normal distribution. The log-normal distribution with mean $\mu$ and variance $\sigma^{2}$ is denoted by $\mathrm{LN}\left(\mu, \sigma^{2}\right)$. As before asset 1 is the riskless bond. For $j \geqslant 2$, we define asset $j$ 's dividend to be

$$
d_{s}^{j}=1 / 3 \cdot 1 / 7 \cdot 1.02 \cdot f_{s}^{j} \cdot \varepsilon_{s}^{j}
$$

and we choose

$$
\begin{aligned}
l_{s}^{h} & \sim \mathrm{LN}\left(2 / 3 \cdot 1.02,(2 / 3)^{2} \cdot 0.01\right), \\
f_{s}^{j} & \sim \operatorname{LN}\left(1, \phi_{j} \cdot 0.0161\right), \\
\varepsilon_{s}^{j} & \sim \operatorname{LN}(1,0.0161) .
\end{aligned}
$$

The actual $\left(f_{s}^{j}\right)_{j=2}^{J}$ are all based on a single realization of a normal random variable. For each asset $j$, we linearly transform the realization of this random variable in such a way that after taking the exponent a log-normally distributed random variable with mean 1 and variance $c_{j} \cdot 0.0161$ results. The construction of the random variables implies that all dividends themselves are log-normally distributed. To get a similar variance of the entire stock market as before, the variance of the factors and the idiosyncratic shock have to be chosen to be 0.0161 instead of 
0.0169. Notice that the factor realization does not enter linearly in the formula for the asset's dividends, an assumption that is made in most models describing factor economies.

We now assume that all agents have CRRA and we draw $\gamma^{h}, h=1,2,3$, from a uniform distribution on the interval $[0.5,10]$. As before we compute 100 examples - Figure $3 \mathrm{a}, \mathrm{b}$ report the analogues of Figures $2 \mathrm{a}, \mathrm{b}$ for the case of log-normal returns.

As before CAPM is a very good prediction for actual equilibrium returns.

\subsection{TWO COMMON FACTORS}

In this subsection we generate a number of economies where risky assets depend on two common factors, $f$ and $\widehat{f}$, and factor loads for each one of the assets are randomly drawn. On top of this, also the importance of the idiosyncratic shock is randomly determined.

We start each example by randomly generating, for each asset $j=2, \ldots, J$, parameters $\phi_{j}, \widehat{\phi}_{j}$, and $i_{j}$. These parameters represent the load in factor 1 , the load in factor 2 and the importance of the idiosyncratic shock. More specifically it holds that

$$
\begin{aligned}
\phi_{j} & \sim \mathrm{U}(0,2), \\
\widehat{\phi}_{j} & \sim \mathrm{U}(0,2), \\
i_{j} & \sim \mathrm{U}(0,4) .
\end{aligned}
$$

Labor income, the two factors and assets' idiosyncratic shocks are independently log-normally distributed, so $l_{s}^{h}, f_{s}, \widehat{f_{s}}$, and $\varepsilon_{s}^{j}$ are drawn from a log-normal distribution,
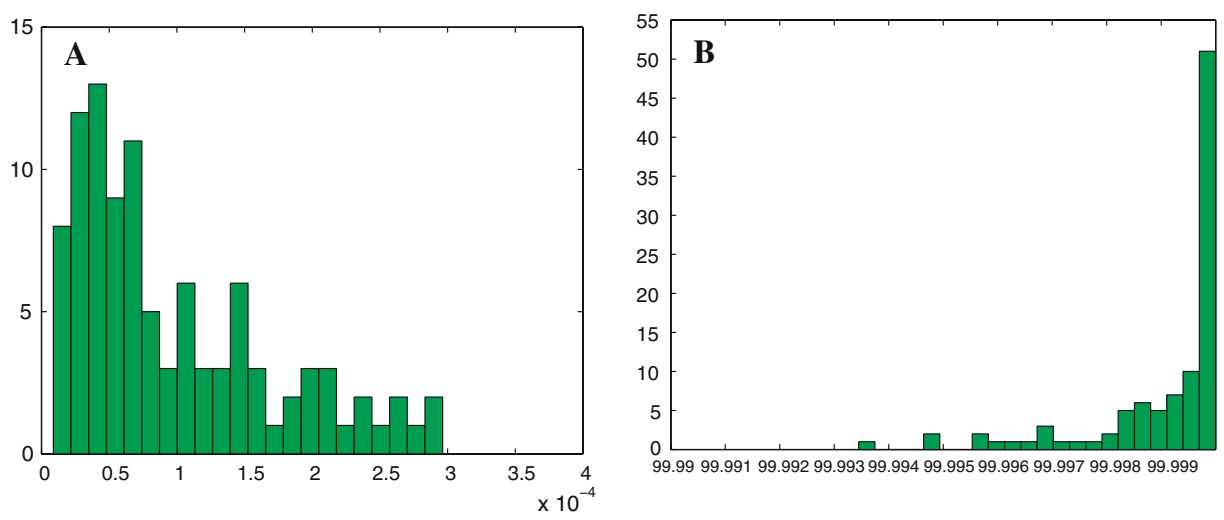

Figure 3. (a) CRRA: MSE, (b) CRRA: 100. Pricing $R^{2}$. 


$$
\begin{aligned}
l_{s}^{h} & \sim \mathrm{LN}\left(2 / 3 \cdot 1.02,(2 / 3)^{2} \cdot 0.01\right), \\
f_{s}^{j} & \sim \mathrm{LN}\left(1, \phi_{j} \cdot 0.0161\right), \\
\widehat{f}_{s}^{j} & \sim \mathrm{LN}\left(1, \widehat{\phi}_{j} \cdot 0.0161\right), \\
\varepsilon_{s}^{j} & \sim \mathrm{LN}\left(1, i_{j} \cdot 0.0161\right) .
\end{aligned}
$$

Finally, dividends are determined by

$$
d_{s}^{j}=1 / 3 \cdot 1 / 7 \cdot 1.02 \cdot f_{s}^{j} \cdot \widehat{f}_{s}^{j} \cdot \varepsilon_{s}^{j} .
$$

The way to generate $f_{s}^{j}, j=2, \ldots, J$, from a single realization of a normally distributed random variable is the same as in Section 4.2. The same applies to the other factor.

Surprisingly, as evidenced by Figure 4, pricing is still a very good prediction for equilibrium returns. Although the asset payoffs now differ substantially from a linear factor structure, pricing errors are very small.

\subsection{OPTIONS}

Since markets are incomplete and utilities are not quadratic, the introduction of an option on one of the assets will generally change all equilibrium prices. Therefore one might expect that the introduction of an option worsens CAPM-pricing considerably. Furthermore, given the robustness of CAPM in the earlier examples, it is interesting to see if it is possible to give an equilibrium pricing formula for options in incomplete markets via CAPM.

Another reason to introduce an option is that this is an asset with the capacity to seriously alter the higher order moments of an asset portfolio. One possible explanation for our results obtained so far is that asset markets are very incomplete, which makes it difficult for households to change the higher order moments of the returns of their portfolios. Although households care for higher
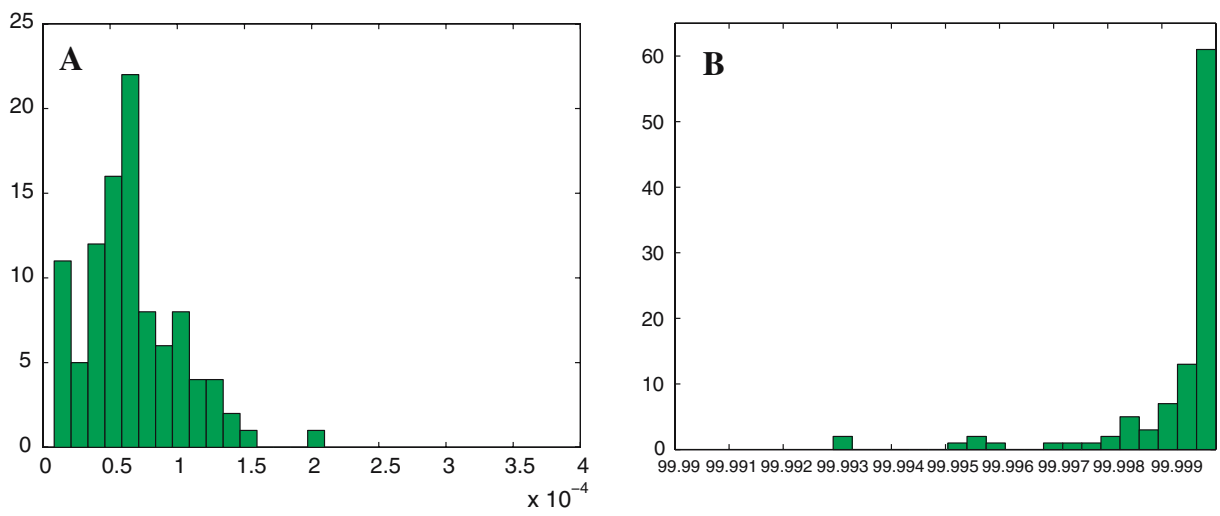

Figure 4. (a) Two-factor: MSE, (b) Two-factor: 100. Pricing $R^{2}$. 
order moments, the mix of marketed assets makes it difficult to affect the higher order moments. With the introduction of an option this clearly changes. Agents have then a possibility to limit downward risk, which is exactly the kind of risk agents with CRRA utility functions are concerned about, but mean-variance optimizers are not.

In order to investigate this issue more closely, we introduce a call option on the most risky asset. Specifically we have a 9 th security which pays $\max \left(d_{s}^{j}-X, 0\right)$ in state $s$, with $X$ the strike price of the call option.

Suppose we consider the uniquely determined equilibrium pricing vector $\pi_{A}^{*}$ of the economy without the option, and we use this pricing vector to price the option. Given the reasoning of the previous paragraph, at those prices one would expect the call option (in combination with the bond) to be more attractive to the agents than the stock, exactly because of the higher order moments. So the equilibrium price of the call option should be higher than the one computed by CAPM-pricing, in order to make that asset less appealing. As a consequence, the expected equilibrium return of the call option should be less than the one predicted by CAPM.

To examine different options, we draw $X$ out of the uniform distribution for each example. To avoid options that are either too far in or too far out of the money we determine in each example the minimal dividend paid out by asset 8 , $\underline{d}^{8}=\min _{s=1, \ldots, S} d_{s}^{8}$, and the maximal dividend paid out, $\bar{d}^{8}=\max _{s=1, \ldots, S} d_{s}^{8}$. We then draw $X$ out of a uniform distribution on $\left[0.5 \cdot\left(1.02+\underline{d}^{8}\right), 0.5 \cdot\left(1.02+\bar{d}^{8}\right)\right]$. Note that 1.02 is the expected dividend of asset 8 . The strike price is always between the average of the minimal dividend and the expected dividend, and the average of the expected dividend and the maximal dividend. The results are given in Figure 5a, b.

The MSE in Figure 5 refers to the MSE of the pricing of the stocks only. The option is analyzed in detail in Figure 6. It turns out that the MSE are comparable to the ones given before. The Pricing $R^{2}$ is somewhat less good than before, but is still excellent.
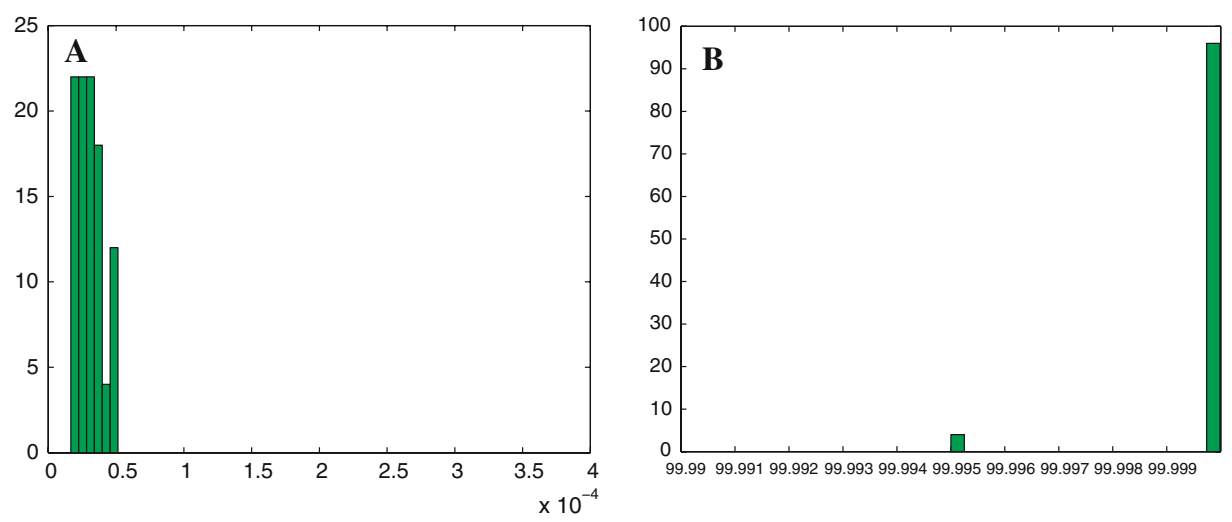

Figure 5. (a) Option: MSE, (b) Option: 100. Pricing $R^{2}$. 


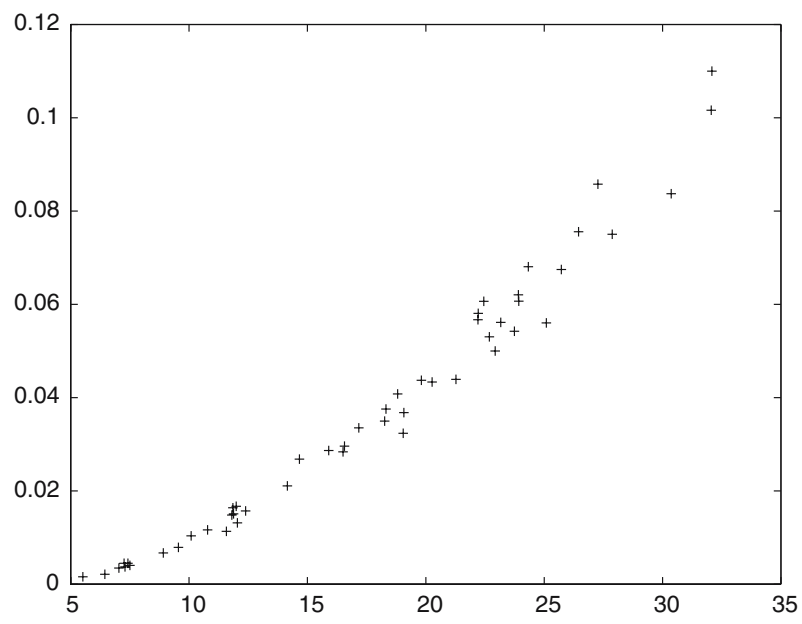

Figure 6. Option: over-prediction of return against option's $\beta$.

Surprisingly, we have found no systematic effect of the introduction of the option on the price of asset 8 . In some examples the introduction of an option raised the price above the CAPM-prediction, in others it has been lower.

Figure 6 analyses the pricing of the option by CAPM. According to CAPM, a call option is a very risky asset. It has zero pay-offs in bad states of nature, and very high in good states of nature. The covariance of a call option with the market portfolio is very high, which is also clear from Figure 6, where it is shown that the option's $\beta$ varied from 5 to 35 in the economies generated. Notice that, as we expected, there is indeed an over-prediction of the expected return of an option by CAPM. In all economies generated, CAPM under-priced the call option. The mis-prediction was relatively small when the option's $\beta$ is low, say below 10 , but may get quite severe for call options with a very high strike price, which are the ones with a high $\beta$. Notice, however, that a higher $\beta$ of an option also corresponds to a higher excess return, which makes the relative mis-prediction less bad. Still, the over-prediction of call option returns is more than linearly increasing in an option's $\beta$, whereas the excess return itself is still roughly linear.

It is surprising that the Pricing $R^{2}$ and the MSEs of stocks remained so good in all economies, even when the option was sometimes seriously under-priced by CAPM. In fact, it may even be perceived as an inconsistency that the Pricing $R^{2}$ is virtually exactly correct, and the option is seriously mis-priced. Indeed, when CAPM-pricing is highly correlated with $\pi_{A}^{*}$, almost all assets are priced very well. The only exceptions are those like options with a very high strike price. Such an asset pays off in a few $(<10)$ states of the 32,768 only. A high correlation with $\pi_{A}^{*}$ is not inconsistent with a fairly different state price in a negligible fraction of states only. 


\section{Conclusions}

In order to show that the CAPM-pricing formula holds exactly in a general equilibrium model with heterogeneous agents, one needs strong assumptions either on preferences or on dividends and endowments (see Berk, 1996). It is possible to construct simple examples with agents who have CRRA utility in which an asset's $\beta$ implies little about its equilibrium excess return.

However, examining the robustness of CAPM by computing equilibria, we find that CAPM provides an excellent approximation to equilibrium excess returns and portfolio-holdings for a wide variety of dividends and endowments. One possible explanation is that the dividend structures we consider are 'close' to a linear factor structure which guarantees that CAPM holds exactly if there is a single agent in the economy and that labor incomes are chosen to be independent of all asset payoffs. Nevertheless, the computational results are very surprising: Both the introduction of heterogeneous agents and substantial deviations from the linear factor structure seem to have very small quantitative effects on the cross section of equilibrium excess returns.

It has already been noted (see e.g. Heaton and Lucas, 1996) that agents' heterogeneity and independent labor background risk has only small quantitative effects on the equity premium. One contribution of this paper is to show that the effects on cross sectional returns are very small as well. The main contribution of this paper, however, is to show that CAPM provides a good approximation of returns for a wide variety of dividend specifications.

\section{Notes}

${ }^{1}$ Herings and Kubler (2000) also consider the CARA-case and find like Levy and Markowitz (1979) that the mean-variance approximation is even more valid there.

${ }^{2}$ When there are redundant assets, a simple arbitrage argument can be used to price them using the prices of the other assets.

${ }^{3}$ For a vector $x \in \mathbb{R}^{m}$ we use the notation $x \geqslant 0$ if $x \in \mathbb{R}_{+}^{m}, x>0$ if $x \in \mathbb{R}_{+}^{m} \backslash\{0\}$, and $x \gg 0$ if $x \in \mathbb{R}_{++}^{m}$.

\section{References}

Ang, A., Chen, J. and Xing, Y. (2005). Downside Risk. Review of Financial Studies, forthcoming.

Arrow, K.J. (1965). Aspects of the Theory of Risk-Bearing, Yrjö Jahnssonin säätio, Helsinki.

Berk, J.B. (1997). Necessary conditions for the CAPM. Journal of Economic Theory, 73, 245-257.

Dittmar, R.F. (2002). Nonlinear pricing kernels, kurtosis preference, and evidence from the cross section of equity returns. Journal of Finance, 57, 369-403.

Fama, E.F. and French, K.R. (1992), The cross-section of expected stock returns. Journal of Finance, 47, 427-465. 
Geanakoplos, J.D. and Polemarchakis, H.M. (1986), Existence, regularity, and constrained suboptimality of competitive allocations when the asset market is incomplete. In Uncertainty, Information and Communication: Essays in Honor of K.J. Arrow, Vol. III, in W.P. Heller, R.M. Starr, and D.A. Starrett (eds.), Cambridge University Press, Cambridge, pp. $65-96$.

Geanakoplos, J. and Shubik, M. (1990). The capital asset pricing model as a general equilibrium with incomplete markets. The Geneva Papers on Risk and Insurance, 15, 55-72.

Heaton, J. and Lucas, D.J. (1996). Evaluating the effects of incomplete markets on risk sharing and asset pricing. Journal of Political Economy, 104, 443-487.

Herings, P.J.J. and Kubler, F. (2000). The robustness of CAPM - a computational approach. METEOR Research Memorandum 00/02, Maastricht University, pp. 1-34.

Herings, P.J.J. and Kubler, F. (2002). Computing equilibria in finance economies. Mathematics of operations research, 27, 637-646.

Levy, H. and Markowitz, H.M. (1979). Approximating expected utility by a function of mean and variance. American Economic Review, 69, 308-317.

Lintner, J. (1965). The valuation of risky assets and the selection of risky investments in stock portfolios and capital budgets. Review of Economics and Statistics, 47, 13-37.

Magill, M.J.M. and Quinzii, M. (1996). Theory of Incomplete Markets, MIT Press, Cambridge.

Mehra, R. and Prescott, E.C. (1985). The equity premium, a puzzle. Journal of Monetary Economics, 15, 145-161.

Oh, G. (1996). Some results in the CAPM with nontraded endowments. Management Science, 42, 286-293.

Samuelson, P.A. (1970). The fundamental approximation theorem of portfolio analysis in terms of means, variances and higher moments. Review of Economic Studies, 37, 537-542.

Sharpe, W.F. (1964). Capital asset prices: A theory of market equilibrium under conditions of risk. Journal of Finance, 19, 425-442.

Tsiang, S.C. (1972). The rationale of the mean-standard deviation analysis, skewness preference, and the demand for money. American Economic Review, 62, 354-371.

Tversky, A. and Kahneman, D. (1992). Advances in prospect theory: Cumulative representation of uncertainty. Journal of Risk and Uncertainty, 5, 297-323.

Willen, P.T. (1997). A model which allows for comparison of different levels of market incompleteness, mimeo, Yale University, New Haven. 